\title{
EFFECTS OF BUS-BASED DISRUPTIVE BUSINESS MODELS WITH LIMITED CAPACITY ON RAIL MONOPOLIES: SOCIAL WELFARE IMPLICATIONS
}

\author{
ALESSANDRO AVENALI ${ }^{1}$, MARTINA GREGORI $^{1,2}$ \& PIERFRANCESCO REVERBERI ${ }^{1}$ \\ ${ }^{1}$ Department of Computer, Control, and Management Engineering “Antonio Ruberti” (DIAG), \\ Sapienza University of Rome, Italy \\ ${ }^{2}$ Department of Mechanical and Aerospace Engineering (DIMA), Sapienza University of Rome, Italy
}

\begin{abstract}
Long distance passenger transport markets are facing important changes as new entrants, e-Platform based bus services retailer (PBSR) operators, are challenging the railway incumbents applying judo economic strategies. Traditionally, European policymakers tended to favour railway services over road services in the long-haul markets, often leading the rail operators in monopolistic-alike positions. Recently, several countries deregulated their national intercity bus markets, gradually introducing intermodal competition in the sector. The competition led to important improvements in service quality, but it also had negative impacts on rail operators' profitability, especially after PBSR operators started to work, due to their disruptive business model based on aggregative online platforms and production externalization. PBSR companies (e.g. Flixbus, BlaBlaBus) are characterized by high flexibility and low production costs, which use as advantage against the incumbents. The rail operators are instead characterized by high indivisibility, high production costs and, usually, big sizes. Losses in either revenues or market shares could easily force them into reducing services quantity or even exit the market. Our paper aims to analyse these new competitive relations in the intercity intermodal market, focusing on resulting impacts on market shares, demand satisfaction and social welfare. Since the bus operators present limited capacity due to technical feasibility (e.g. minimum headway) and the need to limit road congestion (to preserve service quality), the mobility right fulfilment is put in jeopardy. We modelled the competitive relations through game theory, excluding high speed rail from the perimeter to preserve service comparability. Profit levels and optimal social welfare are then studied through simulations. Results confirm that for increasing PBSR production capacity, railway operators tend to have fewer profits or be forced to leave the market, resulting in unsatisfied demand. Furthermore, from a social point of view, the rail monopoly seems to be, under specific circumstances, preferred to a duopoly.
\end{abstract}

Keywords: long distance transport, intermodal competition, judo economics, platform-based bus service retailer, rail services, bus services.

\section{INTRODUCTION}

The European long-haul passenger mobility markets are currently facing important changes. New entrants characterized by disruptive business models are challenging the incumbents, applying judo economic strategies. This study aims to theoretically model the markets' new structure and verify if this structure's attributes could potentially jeopardize the overall social welfare optimization.

Traditionally, European policy makers tended to favour railways services over road services, recognizing subsidies to rail operators and/or applying restrictions on intercity bus services activation. As a result, the role of intercity bus services used to be mainly complementary (qualitatively and/or quantitatively) rather than competitive, and the markets often presented railways operators in monopolistic-alike positions. Recently, several European countries deregulated their national intercity bus markets, gradually introducing intermodal competition in the sector. Early cases of national liberalisation are in the UK, Sweden and Norway, with bus companies free to choose routes, frequencies and fares [1]. 
More recent are, for example, the cases of Germany and Italy, where long-haul bus transports passed from an unknown niche to cover a meaningful role in the intermodal competition [2].

The competition led to important improvements on railways service quality, but it also had negative impacts on rail operators' profitability. Several studies verified that in Germany, even though the number of passengers has been increasing in most recent years, railways are facing a revenue decline associated with the parallel competition with bus [3]. It was indeed also observed that the new competition made especially difficult for niche open-access rail operators to survive [4]. With regards to the bus market concentration and the level of intramodal competition, in some European areas (e.g. Germany, Italy) intercity bus markets could be considered as quasi-monopoly, held by companies with strategic advantages. Bus companies historically active on an area, even before liberalisation, present such type of advantages. However, the most effective position was reached by companies able to apply a new disruptive business model.

The new business model, disruptive for the traditional transport context, is based on online ticketing platforms which consolidate the offer, making easier the interaction between the two sides of the market: production and demand [5]. Companies with this business model could be defined as e-Platform based bus service retailer (PBSR). A PBSR does not own any buses and does not hire any drivers. Instead of owning mobility resources, the PBSR holds revenues shared bi-later contracts with (usually) small independent coach companies. The independent coach companies are operating the transport services, while the PBSR is coordinating their offer and presenting to the clients an integrated and seamless system, through unified sales and marketing operations (which also mainly constitute the costs actually internalized by PBSR). The PBSR business model have used Internet technology innovations to create more customer-oriented services, and has been very successful where adopted [6]. An example of PBSR company is Flixbus, which currently operates all over Europe covering in total more than 2,500 destinations in 31 different countries [7]. In Germany, Flixbus is the leader with a market share of $95 \%$. Another example could be BlaBlaBus, which instead presents a much smaller dimension and started to operate in 2019.

The PBSR strategic advantages over traditional transportation companies can be naturally described by the theory of judo economics. Judo economics was originally introduced by Gelman and Salop [8] to describe a strategy that allows a company to use an opponent's strength to its advantage. An example is the use of credible capacity limitations against large dominant incumbents, which would then find retaliation more expensive than accommodate the entrant. Currently, any advantage generated with a combination of movement (small dimension and agility to anticipate market changes, or act quickly on them), balance (capacity to absorb and contain competitors moves) and leverage (using competitors' strengths against them) can be considered a judo strategy [9]. The application of judo strategies is particularly effective in mature markets, against "slow-moving giants", and it is often linked to technological transitions. These two characteristics well adapt to the European long distance transport market.

The incumbents in the market are railways companies that operated for long in absence of competition, to which is also related a tendency to present large dimensions. The railways operators are usually rigid and their profitability (and sustainability) is sensitive to changes in the demand behaviour. Railways transport production is characterized by high indivisibility (e.g. high vehicles capacity) and high investments (e.g. fleet acquisition, infrastructure access or construction), which make the offer difficult to readjust in a short time and the activation/survival of a services justified only in presence of a sufficiently high level of demand. 
The new entrants in the market are the PBSR companies, for which the investment required to be operative is low, especially in comparison with the competitors (traditional bus companies or railways), while the service characteristics (e.g. small vehicles) and the production costs structure (e.g. not owned fleet), allow for high flexibility [10]. PBSRs are also able to apply lower prices, compared to rail operators. Any significant investment can become a barrier to change, and un-flexible large companies have trouble in matching the same profitability of smaller, cheaper and more flexible competitors [9]. The liberalization, which introduced competition in the market, combined with the PBSRs' judo strategies-alike, could make the rail services production less profitable and force the rail operators into reducing their production, or even exit the market (e.g. according to different level of initial investments). This effect on the incumbent is more likely under specific circumstances, as could be an important demand diversion towards the new entrants' services.

Our paper aims to analyse the intercity intermodal competition between traditional rail systems and PBSR. In particular, our objective is to verify how much and in which way the rail-PBSR competition has an impact on operators market shares, demand satisfaction and social welfare. Concerning the demand satisfaction, an important element to consider is the limited overall capacity that bus operators can offer in the market. The limit in capacity could jeopardize the transport system's ability to fulfil the overall mobility rights (especially if the rail incumbent is forced to reduce/stop the production). The limitations are related to both technical feasibility (e.g. minimum headway, due to safety and coach stations management) and to the need to limit road congestion, to preserve the service quality for clients. In fact, high frequencies could negatively impact in-vehicles travel time, which is already a penalization for the competition with railways services.

In outline, the main issues we attempt to tackle are: (1) identify the conditions for which the rail incumbent is still able to operate in the market after the PBSR's entrance; (2) analyse the effects generated by rail incumbent loss of profitability and/or exit from the market on demand satisfaction and social welfare; and (3) test possible public policies interventions to mitigate the previous negative effects (if occurred).

The intermodal competition between intercity bus and railway services has so not much been systematically explored by scientific research; in particular, not much attention has been dedicated to the impacts of the PBSR disruptive business model. Section 2 delineates the main important elements of the literature on the topic.

To conduct the analysis, we describe the market competitive relations theoretically. Our model is based on Hotelling horizontal differentiation model and includes as distinctive elements the presence of fixed costs (i.e. associated with service activation, while investments are considered as sunk) for the rail operators, and a constraint on production capacity for the PBSR operators. High-speed rail services are excluded from the analysis, as well as connection longer than $300 \mathrm{~km}$ (or that present a relevant difference with bus services in travel time [11]). These restrictions make sure the considered rail and bus services are sufficiently comparable, and could truly represent realistic alternatives for the consumers. Section 3 describes the model, the constraints effect and the implication on demand satisfaction and social welfare. Section 4 analyses the social welfare associated to the new market settings, and argues the application of public policies on the market to enhance social welfare. In Section 5, we summarise our main findings, discuss limitations and define future steps we plan to apply.

\section{RELATED WORK IN LITERATURE}

According to Beria and Bertolin [2], despite its importance the analysis of long-distance transport dynamics and policies has not reached the same understanding of local transport 
services. Previous studies dedicated to the interaction between the bus and rail modes on long-distance paths, following the deregulation processes, were mainly dedicated to price decisions analysis of active market participants [12], [13], the evolution of the intramodal long-haul bus market (e.g. network dimension and density on the territory, market concentration, market composition [3], [10], [14]) and evaluation of the users' willingness to pay for different characteristics of the offered transport services (i.e. surveys, applications of discrete choice modelling [15]). Several studies identified that connections served in parallel by bus and rail negatively impact the level of prices.

A few publications present an approach to the topic similar to ours, but without explicit reference to disruptive PBSRs characteristics in the proposed models. In 2013, Bataille and Steinmetz [16] developed an Industrial Organization model on the long-haul bus-rail competition. The work finds a significant network effect for which the introduction of intermodal competition on single routes may affect other rail services not directly facing competition by buses, leading to unprofitable rail services and possibly the collapse of the entire network. Gremm et al. [17] examine the entry factors for intercity bus companies and price reactions of the incumbent railway company, considering the Germany context. The proposed model account for horizontal product differentiation (variety) for the intramodal competition of bus companies, and vertical differentiation (quality) for intermodal competition, with two-stage equilibrium. The main findings are the tendency for bus companies to operate in niches in which quality advantage of railways is comparatively slow. No elements for the presence of fixed costs or constraints on capacity production for buses seem to be taken into account. Burgdorf et al. [18] proposed a system dynamic simulation model to describe the liberalised long distance transport market. Notably, they tested the possible effects of the application of a road toll for bus services production, aiming to balance the different infrastructure costs sustained by the incumbents rail operators. As respect to our approach, it is not formally presented an analysis on competition and market settings, taking into account PBSRs' business model and limit in capacity.

\section{THE THEORETIC MODEL}

The considered rail and bus services are perfect substitute for the consumers and differ in prices (bus is usually cheaper), perceived quality (e.g. comfort, differences on on-board services) and travel time (rail is usually faster). These three elements are crucial for the consumers' decision over the two alternatives.

\subsection{Market characteristics and models description}

We consider a linear market with length equal to one. In the market are operating a rail company (incumbent) and a PBSR company (new entrant). The model is based on the Hotelling model for horizontal differentiation. Hence, following the principle of maximum differentiation, each company is positioned at one extreme of the linear market (rail operator on 0 , bus operator on 1 (see Fig. 1)). For simplification, the mass of consumers is normalized to one and the consumers are uniformly distributed on the unit linear market. A consumer position on the linear market represents her preference over the service characteristics, showing the mix that would maximize her utility. The distance between the consumer's position and the position of the companies represents her disutility in buying a service not perfectly adherent to the most desirable one. This disutility is modelled as a transport cost the consumer needs to pay to move towards one of the available alternatives, and it is expressed weighting the distance of a fixed factor. In our model, the transport cost factor 


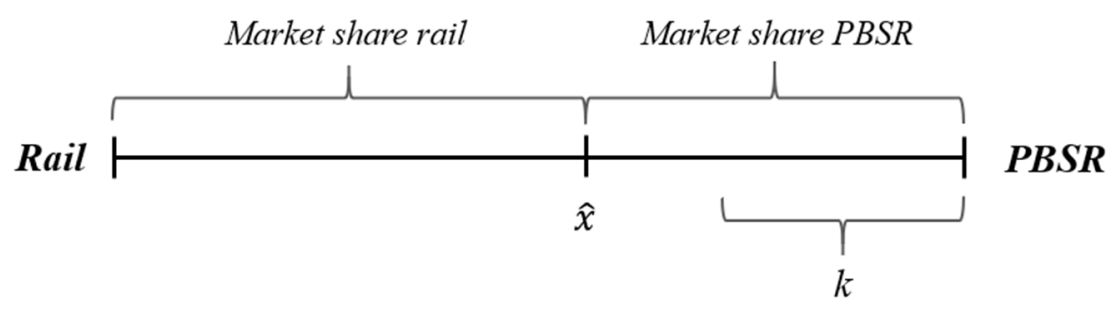

Figure 1: Representation of the constrained duopoly linear market.

towards the bus option is $t$, while the transport costs factor towards the rail option is normalized at 1 . Hence, the $t$ value translates in an indication of preference (and perceived quality) for a certain transport mode over the other, as common in literature. All consumers have the same willingness to pay $\left(u^{*}\right)$. Consumers purchase exactly one unit of service and each consumer decides to buy based on the utility associated to the alternatives (respectively eqn (1), when choosing rail option, and eqn (2) when choosing bus option):

$$
\begin{gathered}
U=u^{*}-p_{r}-x, \\
U=u^{*}-p_{b}-t(1-x) .
\end{gathered}
$$

For the sake of simplicity, we assume that the two competitors face the same unitary cost of production $c$ (cost per one seat); their profits are then expressed by eqns (3) and (4)

$$
\begin{gathered}
\pi_{r}=\left(p_{r}-c\right) * q_{r}-F, \\
\pi_{b}=\left(p_{b}-c\right) * q_{b} .
\end{gathered}
$$

The PBSR companies do not have fixed costs Their variable costs include online platform management, sales operation, marketing and activities for network planning. The railways companies, instead, besides operative costs needs to face also fixed costs associated with services activation (independently from how many rides are run). This cost component is expressed with $F$ and includes fleet acquisition, infrastructure activation (e.g. rail tracks and stations maintenance, while investments in constructions are considered sunk), staff. To be profitable, the rail operator's revenues from sales needs to be at least equal to $F$. However, if it exits the market, it will not be forced to sustain the $F$ cost anymore. On the other hand, as explained in the introduction, the PBSR companies need to face a limit on the overall capacity on output production, that cannot be higher than a threshold $(k)$. The value of $F$ and $k$ will act as constraints on our model.

We apply to the theoretic market four different model forms; we will then use them for comparative analysis on profits and social welfare. First of all, we define two models describing respectively a rail monopoly market and a bus monopoly market. In these cases, each consumer will be able to choose between buying from the monopolist or not to buy at all. We then describe two models of duopoly markets, in which both competitors are active and each consumer can choose between one of the two alternatives and will always buy a unit of service. The first duopoly will not consider constraints on $F$ and $k$, while the second will take them into account. To describe each model behaviour, we need to identify the associated optimal expressions for prices, quantities, profits and social welfare.

As first step, we identify for each model setting the quantity for which consumers are indifferent on their alternatives (buy or not to buy, for monopoly; buy rail or bus service for 
duopoly), equal to the position $\hat{x}$ in the unitary market, for which the utilities of the alternatives have same value. The quantity of indifference is substitute into profits formulas, which are then maximized respect to the prices. For the monopoly models and the unconstrained duopoly, the maximization is unconstrained and it is carried out using the first order condition procedure. For the constrained duopoly, the bus operator optimization is obtained applying for the first order condition to a Lagrangian function taking into account the limit on capacity:

$$
\left\{\begin{array}{c}
\max _{p_{r}}\left(p_{r}-c\right) *\left(\frac{p_{b}-p_{r}+t}{t+1}\right), \\
\max _{p_{b}, \lambda} L\left(p_{b}, \lambda\right)=\left(p_{b}-c\right) *\left(\frac{p_{r}-p_{b}+1}{t+1}\right)+\lambda *\left(k-\frac{p_{r}-p_{b}+1}{t+1}\right) .
\end{array}\right.
$$

Finally, social welfare is composed of the companies' profits (net from production costs) and the consumer surplus, which is a measurement of the consumers benefit in buying a unit of service on the market. This benefit is calculated as the cumulative difference between the consumers' maximum willingness to pay and the paid price. All the obtained expressions, describing the main important variables of the four models, are reported in Table 1.

\subsection{Duopoly: Constraints influence on market equilibrium}

Our models strictly depend on the values assumed by five parameters: the willingness to pay $u^{*}$, the unitary cost $c$, the relative preference over bus or rail $t$, and the two thresholds $F$ for rail minimum revenues and $k$ for maximum PBSR's capacity. In this subsection, we investigate for which values of $F$ and $k$ the duopoly can be applied.

We start examining the unconstrained duopoly. In this scenario, no constraint is applied; it then follows that the duopoly can always be realized and both the companies are free to choose the quantity of service to produce. The PBSR is not constraint in capacity and the rail operator's fixed costs $F$ are assumed to always be small enough to not harm the profitability.

The competitors market shares depend then on parameter $t$, which signals which of the alternative is preferred by consumers as perceived having a higher quality. Considering the expressions for prices, quantities and profits for the unconstrained duopoly displayed in Table 1, it follows that:

$$
\begin{array}{ll}
\text { if } 0<t<1 & p_{r}<p_{b}, q_{r}<q_{b}, \pi_{r}<\pi_{b}, \\
\text { if } \quad t=1 & p_{r}=p_{b}, q_{r}=q_{b}, \pi_{r}=\pi_{b}-F, \\
\text { if } \quad t>1 & p_{r}>p_{b}, q_{r}>q_{b}, \pi_{r}<\pi_{b}, \\
\text { if } \quad t>3 F+1 & p_{r}>p_{b}, q_{r}>q_{b}, \pi_{r}>\pi_{b} .
\end{array}
$$

The company producing the most preferred alternative is able to fix higher prices and cover higher portion of the market demand. The rail operator is able to copy and outdo the PBSR profits only if $t$ is sufficiently high (rail service perceived having higher quality), with respect to the fixed costs $F$.

We first introduce in the scenario the capacity constraints only, while the constraint on $F$ is not considered. The PBSR can then serves only a $k$ percentage of the market. From profits maximization for constrained duopoly (see eqns (5) and (6)) we know that the capacity constraint is active when the corresponding Lagrangian multiplier $\lambda$ is positive, which lead to: 


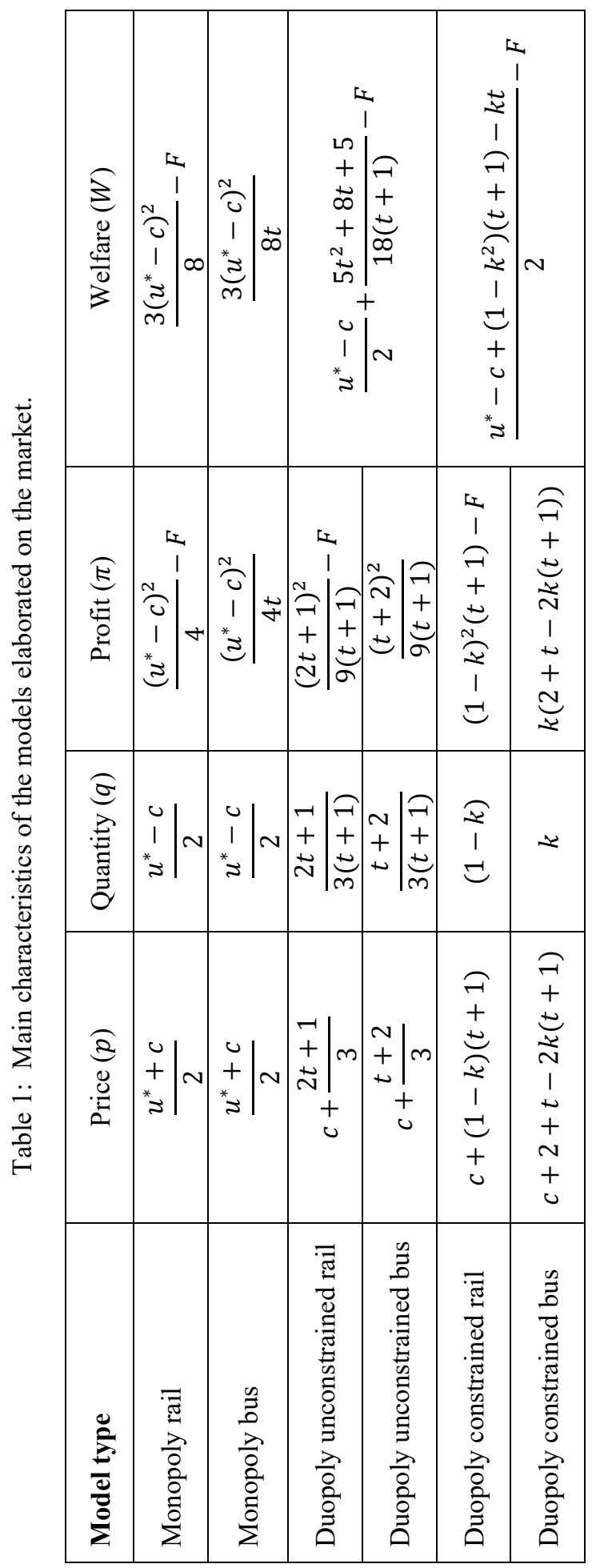




$$
k<\frac{2+t}{3(t+1)} \text { then: } k \in\left(0, \frac{2}{3}\right) \text { if } 0<t<1 \text { and } k \in\left(0, \frac{1}{2}\right) \text { if } t>1
$$

The left side of Fig. 2 displays both under which conditions the PBSR exists in the market (red area) and the demand evolution according to parameter $t$ (red line, since $q_{b}=k$ in constrained duopoly). The white area above the red line and below the blue dashed line represents the demand share that cannot be served by the PBSR, either in monopoly or duopoly. Always referring to Table 1, it is easy to show how the rail operator price, market share and profits decline in $k$, since the PBSR option would be selling to a larger percentage of consumers. Also the PBSR price decreases in $k$.

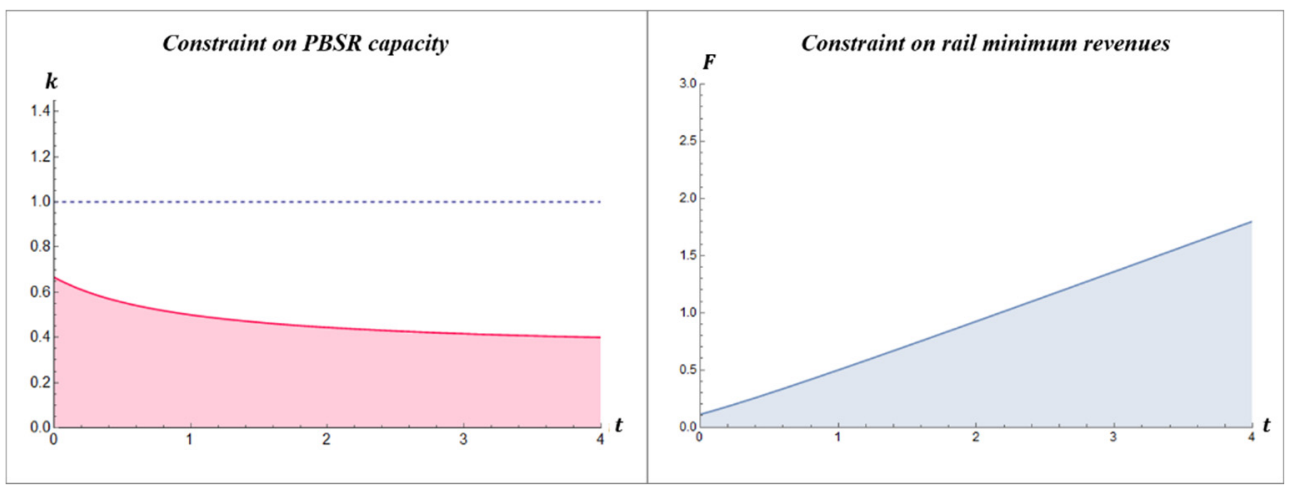

Figure 2: Constraints over PBSR capacity and rail operator revenues if applied separately.

Nevertheless, for small values of $k$ (lower than a threshold: $k<(2+t) / 4(t+1)$ ), this effect is balanced by the increment in market share and the profits are then increasing in $k$.For higher value of $k$, instead, the PBSRs' profits are decreasing.

We now introduce in the scenario the constraint on fixed costs $F$ for the rail operator, while the constraint on $k$ is not considered. To be profitable, the rail operator's revenue from sales needs to be higher than the fixed costs. If the constraint is not respected, the operator is forced to exit the market. Since the PBSR operator has no limit on capacity, we can apply the unconstrained duopoly to quantify the revenues from sales, and thus obtain:

$$
F \leq \frac{(1+2 t)^{2}}{9(t+1)} \text { then: } F \in\left(0, \frac{1}{2}\right) \text { if } 0<t<1 \text { and } F \in\left(\frac{1}{2}, \infty\right) \text { if } t>1 .
$$

Hence, the constraint is more severe when the bus option is perceived as having higher quality (see the blue area on the right side of Fig. 2), and the production is more sustainable as $t$ increases.

We now introduce both the constraints $(k, F)$ in the scenario at the same time. The constraints define for which parameters combinations each market model setting is appliable (i.e. monopoly, unconstrained duopoly, constrained duopoly). The competitors will then strategically choose the best option among the available alternative to maximize their profits, taking into account each other behaviour. Before proceed, we verify which duopoly alternative (unconstrained or constrained) is strategically preferable for the competitors:

$$
\pi_{r_{-} \text {unc_duop }}<\pi_{r_{-} \text {const_duop }} \quad \text { always, }
$$




$$
\begin{array}{ll}
\pi_{b_{-} u n c_{-} d u o p}>\pi_{b_{-} \text {const_duop }} & \text { if } k<\frac{2+t}{6(t+1)}, \\
\pi_{b_{-} u n c_{-} \text {duop }}<\pi_{b_{-} \text {const_duop }} & \text { if } \frac{2+t}{6(t+1)}<k<\frac{2+t}{3(t+1)} .
\end{array}
$$

In a duopoly setting, the rail operator would always prefer to act under active constraints, since it will be able to reach higher market share due to the PBSR limit in capacity. The PBSR operator, instead, would prefer to not act under active constraints, if its capacity is strictly limited (with a threshold decreasing in $t$ ).

Following constrained duopoly characteristic in Table 1, the constraints have the form:

$$
\text { constraints } \rightarrow k<\frac{2+t}{3(t+1)} \text { and } F \leq(1-k)^{2}(t+1) \text {. }
$$

Fig. 3 displays the constraints evolution (simulating a scenario in which $F=1$ ) and the market setting applied for each parameters combination. The rail operator cannot operate above the blue line. When it is active in the market, there could be either a constrained duopoly (violet area) or, only above a certain threshold of $k$ (according to left side of eqn (15)), an unconstrained duopoly (blue area). Above the blue line, only the PBSR operator can be active in a monopoly setting, which could be either limited or not limited in capacity.

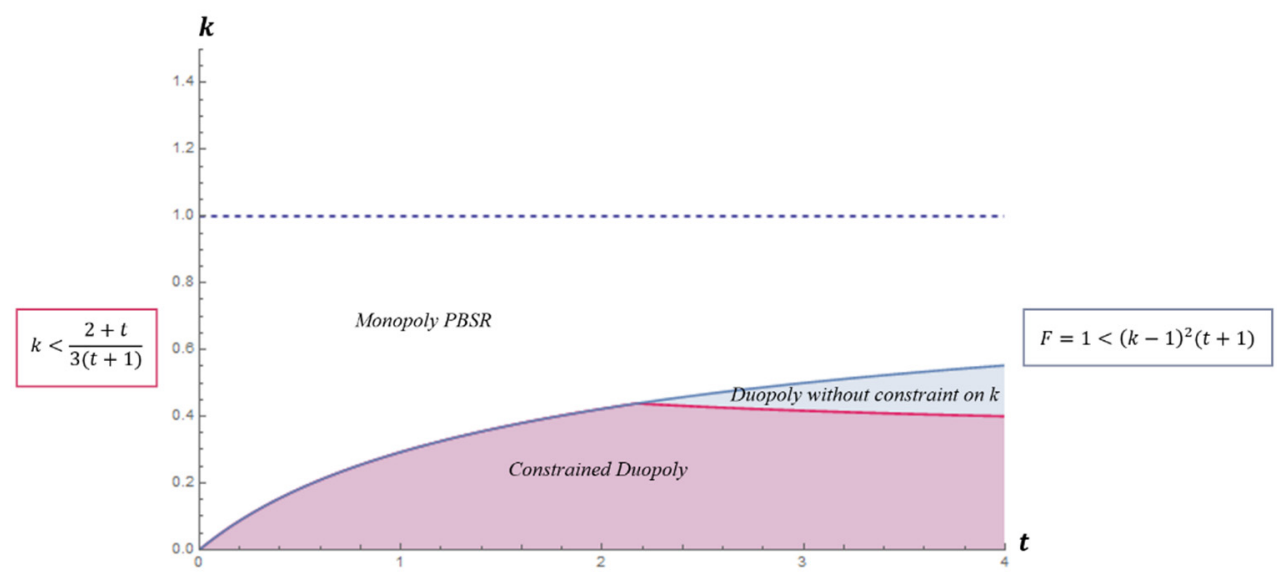

Figure 3: Market setting according to parameters values and constraints (for $F=1$ ).

\section{SOCIAL WELFARE IMPLICATIONS}

The identified market settings should be tested to verify if they correspond to the best alternatives for the social welfare point of view. We would like to focus on two particularly interesting cases: the constrained duopoly (violet area in Fig. 3), and the PBSR monopoly (white area in Fig. 3).

The constrained duopoly is allowed by the bus market liberalisation. We aim to verify if there is any parameters' combination for which the previously active alternative, the rail monopoly, would be preferable on the social welfare point of view:

$$
W_{\text {mono_rail }}>W_{\text {const_duop }} \text {. }
$$

The $W_{\text {const_duop }}$ value depends on all the 5 main model parameters (see Table 1 ). Then, to simplify the analysis, we run the test in a simulated scenario, in which we fix the values of 
the unitary variable cost of production $(c=0)$ and the railways production fixed costs $(F=$ 1 ). We contain the analysis on the parameters ranges for which the constrained duopoly is appliable (both constraint on $k$ and $F$ are active), and we make sure that the level of willingness to pay is always high enough to be coherent with the models settings:

$$
u^{*}>p_{\text {const_duop }_{i}}+t * k, i=\text { rail, PBRS. }
$$

The threshold for $u^{*}$ is identified as the sum of price paid to buy a unit of service from the company $i$, plus the maximum transport costs faced by the last consumer buying from $i$. This transport cost is fixed to $t * k$, as the PBSR company cannot serves more than $k$ percentage of the market, and the last consumer to buy could then be positioned at most in $k$. We run the test for the two main parameter $t$ ranges: $t \in(0,1)$, for which the bus is preferred over the rail option, and $t>1$, for which the rail is preferred over the bus option. Fig. 4 shows the obtained results. Overall, the social welfare associated with $W_{\text {mono_rail }}$ appears to be higher than $W_{\text {const_duop }}$. (see green areas), and it also increases more rapidly in $t$. Nevertheless, when the bus is the most preferable option, the condition is verified only for limited values of $F$. While, when the rail is the most preferable option, there are always combinations of $t$ and $k$ which verify the condition for any positive $F$. The condition is verified only for high enough values of $u^{*}$, with thresholds depending on $t$ and $k$.

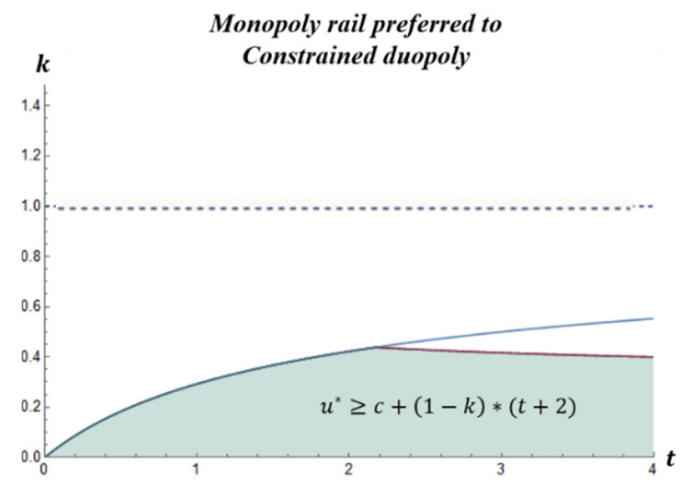

Figure 4: Analysis testing optimal social welfare on simulated scenarios.

Concerning the second case, if the PBSR monopoly is active, a part of the demand is systematically not satisfied. The bus company could have a technically limited capacity, while the rail company cannot profitably operate in the market.

Then, the possible negative effect on mobility right fulfilment could be mitigated guaranteeing to the rail company sufficient economic sustainability. Possible ways to achieve the railways' survival in the market are the use of public subsidies in favour of railway operators and/or the imposition of compensation procedures between competitors. For example, the PBSR profits could be taxed and the collected economic resources could be transferred to the rail operator as compensation - partial or total - of its loss due to the presence of fixed costs. We test the possibility to apply a flat compensation between the competitors (for which, $F$ is burden by both companies). To do so, we relax the constraint on rail operator minimum revenues from sales, while excluding ranges for which the PBRS monopoly is already the selected option: 


$$
\begin{gathered}
F \leq\left(1-k^{2}\right)(t+1)+k(2+t-2 k(t+1)), \\
F>\left(1-k^{2}\right)(t+1) .
\end{gathered}
$$

We aim to verify if there is any parameters' combination for which the constrained duopoly market setting should be preferred to the PBSR monopoly on the social welfare point of view:

$$
W_{\text {const_duop }}>W_{\text {mono_PBRS }} \text {. }
$$

Again, we fix the values of $c(=0)$ and $F(=1)$ as simplification and study the social welfare values over the simulated scenario. We impose coherent values for the willingness to pay $u^{*}$ (see eqn (18)) and we contain the analysis of the parameters over ranges for which the PBSR constrained monopoly is applicable (considering that the constraint on $F$ is substituted by eqns (19) and (20)). Results seem to show that the $W_{\text {mono PBRS }}$ (without restriction over $k$ ) would always be the best option in terms of social welfare (if minimum thresholds on $u^{*}$ values, depending on $t$ and $k$, are respected), while the constrained duopoly seems to be never preferable. We believe that in condition of severe capacity constraint over PBSR production, the social welfare would be better off by a passage to a constrained duopoly market setting, since more people would be served with similar or lower applied ticket prices. Furthermore, this preference over constrained duopoly should increase as the rail option is more and more preferable to the bus option for the passengers (i.e., $t$ increases).

The obtained results derive from the assumptions and simplifications we needed to adopt in our theoretic model and on our simulations. There could then be limitations in representativeness. In particular, in our second test it is assumed that the rail operator either is active in the market at the full capacity to cover its market share or it is forced to leave the market as a whole. However, in a real context a rail company before exit the market would rather try at first to limit the fixed costs negative effect on profitability modulating its offer, and in doing so delineating a much smoother process of adaptation of progressively reduce its investments. For example, the rail company could dismiss part of the fleet and/or reduce frequencies or number of rides. Furthermore, it is possible that public policies alternative to the flat compensation could be more adequate interventions to economically sustain the railways' production (e.g. a variable compensation based on market shares and connected to infrastructure use, as hypothesized by Burgdorf et al. [18]).

\section{DISCUSSIONS AND FUTURE STEPS}

The deregulation of intercity bus transport introduced intermodal competition on long distance passengers markets, which were previously mainly dominated by rail operators solely. The e-Platform Bus Service Retailers, characterized by a disruptive business model, are challenging the incumbents applying judo strategies. The PBSRs use their flexibility and low production costs against the rail operators, characterized instead by high indivisibility and investments, that could be pushed out of the market by a reduction in profitability and/or market share. We modelled these new competitive relations using game theory and including PBSRs' limits in production capacity and the presence of fixed costs for rail operators. Profits level and optimal social welfare scenarios were then studied through simulations Results confirm that for increasing PBSR production capacity, railway operators tend to have fewer profits or be forced to leave the market, possibly resulting in unsatisfied demand. Furthermore, from a social point of view, the rail monopoly seems to be, under specific circumstances, preferred to a duopoly. The representativeness of our results could be limited by the simplifications adopted on the theoretic model. The main issue is the assumption of an "in-or-out" behaviour for the rail operator, that is not allowed to limit the fixed costs 
negative effect on profitability modulating its offer. Further analysis should then include the definition of a more realistic simulation flow-chart and test also the applications of policies alternative to flat compensation. We plan to set a simulation that would take into account demand behaviour, production costs and competitive interactions, and allowing a progressive reduction in investments for the rail operator. Analogous effects to the one generated by PBSR disruptive business model on rail operators could be identified in other transportation contexts. On long distance markets, the presence of ridesharing services (e.g. BlaBlaCar) could contribute to increasing the demand diversion from rail operators. In future work, their role could then be included in the market setting. In the urban context, a similar interaction could happen between public transport and the micro-mobility modes. Bike-sharing services and e-scooter sharing services have been rapidly growing. It would be important to analyse this phenomenon, that has been subjected in the last period to an important acceleration. Worldwide, several public authorities are fostering micro-mobility as part of the measures to mitigate negative effects on transport due to the Covid-19 pandemic emergency (e.g. increments in dedicated infrastructures, subsidies to final users, applied for example in Italy).

\section{ACKNOWLEDGEMENT}

The financial support of Sapienza University of Rome (through the Sapienza Awards no. AR11916B877B0160) is gratefully acknowledged.

\section{REFERENCES}

[1] Beria, P., Grimaldi, R., Debernardi, A., Ferrara, E. \& Laurino, A., Spatial and scenario analyses of long distance coach transport in Italy. MPRA Working Paper, no. 54739, 2014.

[2] Beria, P. \& Bertolin, A., Evolving long-distance passenger services: Market concentration, fares and specialisation patterns in Italy. Research in Transportation Economics, 74, pp. 77-92, 2019.

[3] De Haas, S. \& Schäfer, J.T., Consolidations in the German interurban bus industry: Effects on prices and quantities. MAGKS Joint Discussion Paper Series in Economics (No. 31-2017), Philipps-University Marburg, School of Business and Economics, Marburg, 2017.

[4] van de Velde, D. \& Karl, A., Workshop 3 report: Market initiative regimes in bus, coach and rail: Recent developments, threats, developing paradigms and regulatory needs. Research in Transportation Economics, 69, pp. 254-259, 2018.

[5] Willing, C., Brandt, T. \& Neumann, D., Electronic mobility market platforms: A review of the current state and applications of business analytics. Electronic Markets, 27(3), pp. 267-282, 2017.

[6] Guihéry, L., Long distance coach services in France and Germany: The new European competition between Flixbus and BlaBlaBus. Rivista di Economia e Politica dei Trasporti, 1, 2019.

[7] Flixbus, About FlixMobility. www.global.flixbus.com/company/about-flixbus. Accessed on: 9 Jun. 2020.

[8] Gelman, J.R. \& Salop, S.C., Judo economics: Capacity limitation and coupon competition. The Bell Journal of Economics, pp. 315-325, 1983.

[9] Yoffie, D.B. \& Kwak, M., Judo strategy: 10 techniques for beating a stronger opponent. Business Strategy Review, 12, pp. 20-30, 2002.

[10] Blayac, T. \& Bougette, P., Should I go by bus? The liberalization of the long-distance bus industry in France. Transport Policy, 56, pp. 50-62, 2017. 
[11] Gremm, C., Impacts of the German interurban bus market deregulation on regional railway services. Proceedings of the International Conference Series on Competition and Ownership in Land Passenger Transport, Stockholm, Sweden, 2017.

[12] Gremm, C., The effect of intermodal competition on the pricing behaviour of a railway company: Evidence from the German case. Research in Transportation Economics, 72, pp. 49-64, 2018.

[13] Beria, P., Nistri, D. \& Laurino, A., Intercity coach liberalisation in Italy: Fares determinants in an evolving market. Research in Transportation Economics, 69, pp. 260-269, 2018.

[14] Fageda, X. \& Sansano, S., Factors influencing prices and frequencies in the interurban bus market: Evidence from Europe. Transportation Research Part A: Policy and Practice, 111, pp. 266-276, 2018.

[15] Hasiak, S., Hasiak, F. \& Egea, A., Coach and train: Differences in individuals perception of these modes. Transportation Research Procedia, 14, pp. 1706-1715, 2016.

[16] Bataille, M. \& Steinmetz, A., Intermodal competition on some routes in transportation networks: The case of inter urban buses and railways. DICE Discussion Paper, No. 84, 2013.

[17] Gremm, C., Bälz, D., Corbo, C. \& Mitusch, K., Intermodal competition between intercity buses and trains: a theoretical model. KIT Working Paper Series in Economics, 135, 2019.

[18] Burgdorf, C., Eisenkopf, A. \& Knorr, A., User acceptance of long distance bus services in Germany. Research in Transportation Economics, 69, pp. 270-283, 2018. 